\title{
Pathophysiology of Acute Experimental Pancreatitis: Lessons from Genetically Engineered Animal Models and New Molecular Approaches
}

\author{
Claus Schäfer Anne Barbara Tietz Burkhard Göke \\ Department of Internal Medicine II, Klinikum Grosshadern, Ludwig Maximilians University Munich, \\ Munich, Germany
}

\section{Key Words}

Pancreatitis $\cdot$ Cytokines $\cdot$ Heat-shock proteins .

Transgene

\begin{abstract}
The incidence of acute pancreatitis is growing and worldwide population-based studies report a doubling or tripling since the 1970 s. $25 \%$ of acute pancreatitis are severe and associated with histological changes of necrotizing pancreatitis. There is still no specific medical treatment for acute pancreatitis. The average mortality resides around $10 \%$. In order to develop new specific medical treatment strategies for acute pancreatitis, a better understanding of the pathophysiology during the onset of acute pancreatitis is necessary. Since it is difficult to study the early acinar events in human pancreatitis, several animal models of acute pancreatitis have been developed. By this, it is hoped that clues into human pathophysiology become possible. In the last decade, while employing molecular biology techniques, a major progress has been made. The genome of the mouse was recently sequenced. Various strategies are possible to prove a causal effect of a single gene or protein, using
\end{abstract}

C.S. and A.B.T. contributed equally to the work.

\section{KARGER}

Fax +4161306 1234 E-Mail karger@karger.ch www.karger.com (c) 2005 S. Karger AG, Basel 0012-2823/05/0713-0162\$22.00/0

Accessible online at:

www.karger.com/dig either gain-of-function (i.e., overexpression of the protein of interest) or loss-of-function studies (i.e., genetic deletion of the gene of interest). The availability of transgenic mouse models and gene deletion studies has clearly increased our knowledge about the pathophysiology of acute pancreatitis and enables us to study and confirm in vitro findings in animal models. In addition, transgenic models with specific genetic deletion or overexpression of genes help in understanding the role of one specific protein in a cascade of inflammatory processes such as pancreatitis where different proteins interact and co-react. This review summarizes the recent progress in this field.

Copyright (C) 2005 S. Karger AG, Basel

\section{Introduction}

In vivo models are an indispensable addition to in vitro research findings. For translational research with applications to clinical aspects, a confirmation of findings from cells and bacteria is a prerequisite prior to clinical tests. Transgenic animals enable the study of specific genes (and in consequence, proteins) of interest. The two main categories of transgenic animals can be divided into gain-of-function (i.e., overexpression of the protein of interest) or loss-of-function models (i.e., genetic deletion of 
Table 1. Overview of the different cytokines and their effects

\begin{tabular}{|c|c|c|c|}
\hline Transgeneity & Experimental model & Result & Group (first author) \\
\hline IFN- $\gamma$ & Overexpression & Transient upregulation of EGF, TGF- $\alpha$ and EGF receptors, fibrosis & Arnush, 1996 [38] \\
\hline IFN- $\gamma$ & $\begin{array}{l}\text { Overexpression and IFN- } \gamma \\
\text { antibody administration }\end{array}$ & $\begin{array}{l}\text { Lowers the mitotic index of pancreatic ducts and islet cells, reduces } \\
\text { elevated blood glucose levels }\end{array}$ & $\mathrm{Gu}, 1995$ [39] \\
\hline TGF- $\alpha$ & Overexpression & Fibrosis, formation of duct-like tubular complexes & Ebert, 1999 [46] \\
\hline $\begin{array}{l}\text { Double transgenic for } \\
\text { TGF- } \alpha \text { and TGF- } \beta_{1}\end{array}$ & Overexpression & Dramatic decrease of $\beta$-cells and development of diabetes & Sanvito, 1995 [47] \\
\hline TGF- $\beta_{1}$ & Overexpression & $\begin{array}{l}\text { Accumulation of extracellular matrix, massive fibrosis, cellular infiltrates } \\
\text { of macrophages and neutrophils, inhibition of acinus cell proliferation, } \\
\text { impaired TGF- } \beta \text { signaling, contribution to autoimmune pancreatitis }\end{array}$ & $\begin{array}{l}\text { Vogelmann, } 2001[48] \\
\text { Sanvito, } 1995[47] \\
\text { Lee, } 1995 \text { [49], } \\
\text { Hahm, } 2000 \text { [43] }\end{array}$ \\
\hline TGF- $\beta$ receptor & $\begin{array}{l}\text { Overexpression of dominant } \\
\text { negative mutant from of the } \\
\text { TGF- } \beta \text { receptor }\end{array}$ & $\begin{array}{l}\text { Increase in MHC class } 2 \text { molecules, increased susceptibility to cerulein- } \\
\text { induced pancreatitis, T- and B-cell hyperactivation, IgG autoantibodies } \\
\text { against acinar cells and IgM autoantibodies against pancreatic ductal } \\
\text { epithelial cells, loss of growth inhibitory and gene induction responses }\end{array}$ & Bottinger, $1997[50]$ \\
\hline IL-1 & $\begin{array}{l}\text { Homozygous knockout of } \\
\text { the ICE gene }\end{array}$ & Increased survival & Norman, 1997 [51] \\
\hline IL-1 receptor & IL-1 receptor deletion & $\begin{array}{l}30--50 \% \text { greater levels of IL- } 1 \text { mRNA in knockouts as compared to } \\
\text { wild-type animals, attenuated pancreatitis and lower IL-6 levels }\end{array}$ & Norman, $1995[52,53]$ \\
\hline IL-6 & $\begin{array}{l}\text { Pretreatment with an } \\
\text { anti-IL-6 antibody }\end{array}$ & $\begin{array}{l}\text { Reduces pancreatic edema in mice with a LPS + cerulein-induced } \\
\text { pancreatitis }\end{array}$ & Suzuki, $2000[55]$ \\
\hline IL-6 & Knockout mouse & $\begin{array}{l}\text { Higher plasma levels of TNF- } \alpha \text { and IL- } 1 \beta \text {, higher degree of oxidative } \\
\text { and nitrosative tissue damage, more severe tissue injury and an } \\
\text { increased mortality rate }\end{array}$ & Cuzzocrea, 2002 [56] \\
\hline IL-10 & $\begin{array}{l}\text { Knockout mouse, } \\
\text { KC blockade }\end{array}$ & $\begin{array}{l}\text { No effect on the degree of edema, neutrophil infiltration and histological } \\
\text { lung changes, all effects are more severe in knockout animals as } \\
\text { compared to C } 57 \mathrm{BL} / 6 \mathrm{~J} \text { mice }\end{array}$ & Gloor, 1998 [57] \\
\hline MAPKAP-2 & Knockout mouse & $\begin{array}{l}\text { Drastically reduced IL- } 6 \text { and TNF- } \alpha \text { levels in the serum of knockout } \\
\text { animals and histological protection against pancreatitis }\end{array}$ & Tietz, 2004 [58] \\
\hline
\end{tabular}

the gene of interest). A transgenic mouse or rat has a transgene in addition to its normal complement of genes. A transgene is an artificial gene cloned by recombinant DNA technology and microinjected into fertilized mouse or rat eggs. Eggs are transferred into foster mothers for gestation. Transgenic progeny are bred to produce a line. Transgenes integrate randomly into chromosomal DNA and are transmitted as a Mendelian trait. For tissue-specific protein expression, a construct with a specific promoter can be used, for example the elastase promoter for specific expression in exocrine acini. For expressing proteins in a wide variety of tissues, a CMV promoter can be used. In addition, our own observations (see below) and the data from Natori et al. [1] showed that using a CMV promoter can result in a highly specific protein expression in exocrine pancreatic acini. Gene-targeted mice are derived from embryonic stem (ES) cells. ES cells are ma- nipulated in culture by introducing a targeting vector that is cloned in the laboratory by recombinant DNA technology. The targeting vector DNA precisely replaces a segment of chromosomal DNA (hence the name 'gene targeting') in the ES cell. ES cells are injected into a normal mouse blastocyst where they mingle with the embryo's cells to form the developing mouse. Up to $100 \%$ of the resulting mouse chimera can be formed from cells descended from the ES cells. ES cell-derived mouse chimeras are bred to normal mice to produce progeny carrying the targeted gene which is transmitted as a Mendelian trait. The advantage of generating transgenic animals is the less time-consuming protocol. The 'biological effects' of overexpressing a protein are interpretable as gain of function except when there is no phenotype obvious. The disadvantage of transgenic animals is that the transgene can interfere with other genes and therefore interpreta- 


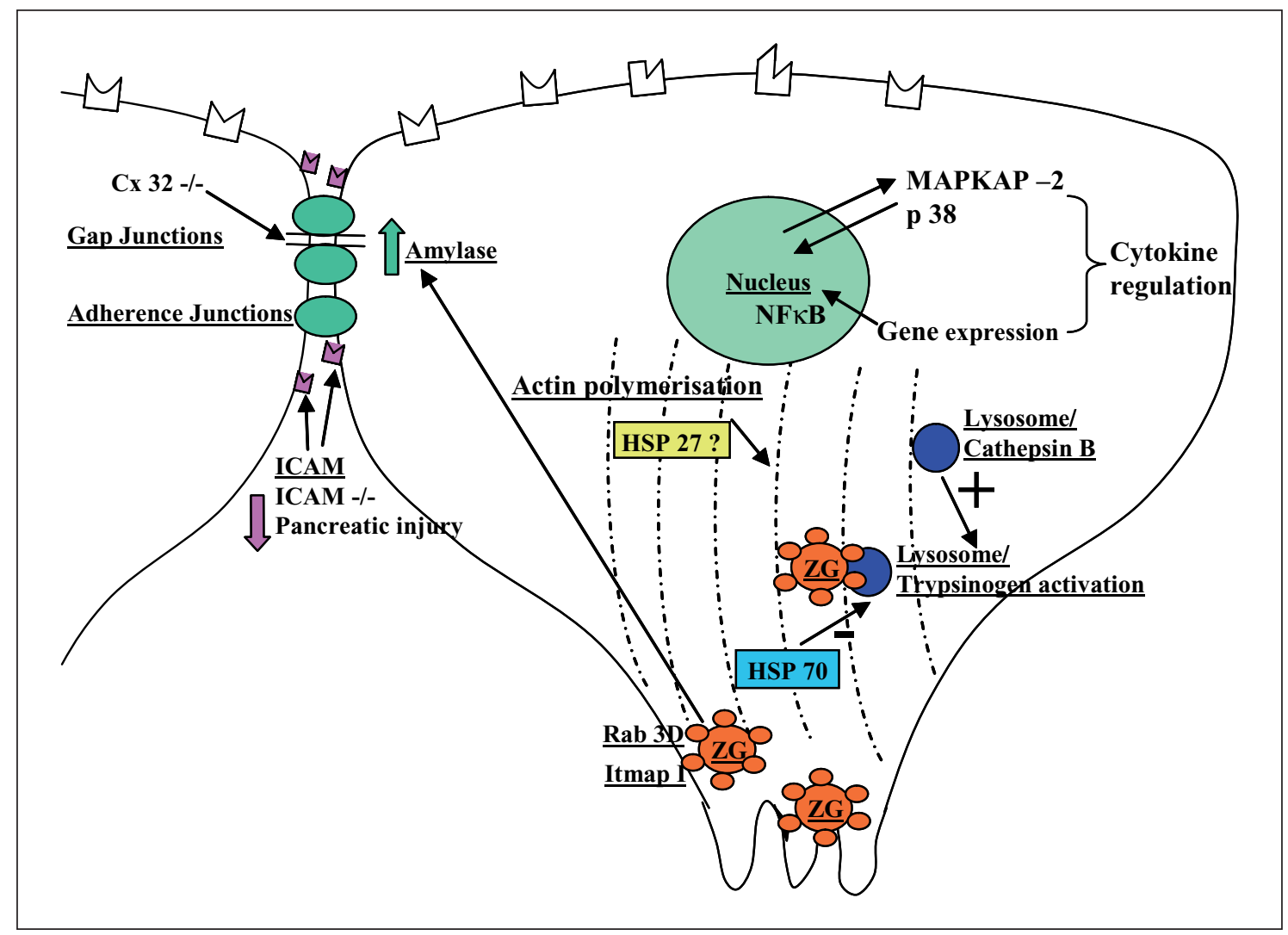

Fig. 1. Selected variables affecting acute pancreatitis. Gene expression is regulated by NFKB among other transcription factors. Activation of p38 and MAPKAP-2 regulates cytokine levels and therefore influences the severity of pancreatitis. Lysosome and zymogen granula colocalization results in early trypsinogen activation that can be inhibited by Hsp70. Cx32-/ leads to elevated amylase levels just as Rab3D and Itmap1. Knockout of intercellular adhesion molecules (ICAMs) results in milder pancreatic injury. Disruption of the actin cytoskeleton and actin polymerization is protected by overexpression and phosphorylation of Hsp27.

tion can be difficult. One of the major problems by generating knockout animals is that the gene can be lethal or that the embryonic development is influenced by other gene interactions as a result of the missing gene [for details see 2].

Especially in inflammatory processes like pancreatitis where subsequent processes and cascades are regulated by different factors and interacting molecules, in vivo models focusing on just a single gain or loss of function protein are of great interest. Transgeneities involved and studied in pancreatitis focuses on different levels in the regulation of secretion in exocrine pancreatic acini. This review focuses on the following aspects:

Structural proteins are involved in the development and maintenance of pancreatitis. Such proteins are regulated by the stimulus-secretion coupling of the single acinus and are touched during the regulation of exocytosis in clusters of acini. Examples of genetic deletions within two genes encoding for structural proteins, $\mathrm{Cx} 32$ and ICAM, on amylase secretion are reported.

Beside the cell contact proteins, zymogen granule proteins are involved in exocytosis. The small GTPase Rab3D and a new protein, Itmap1, are localized on the zymogen granule membrane and affect amylase secretion.

Proteases like cathepsin B are believed to be involved in intracellular activation of trypsinogen and thereby may contribute to development of acute pancreatitis.

Induction and colocalization of the stress protein Hsp70 with lysosomes attenuates trypsinogen activation. Another heat-shock protein, Hsp27, which can regulate actin polymerization in vitro, also ameliorates acute pancreatitis when it is overexpressed and phosphorylated in exocrine pancreatic acini. 
Cytokines are involved in mediating the inflammatory process during pancreatitis and some of them are induced and expressed in pancreatic acini. The p38 MAP kinase and MAPKAP kinase-2 are important signal transduction pathways for regulating TNF- $\alpha$ and interleukin (IL)-6. Inhibition of TNF- $\alpha$ and other cytokines attenuates acute pancreatitis. An overview of the different cytokines and their effects is given in table 1. Figure 1 shows a scheme of the different effector proteins modified in pancreatic acini. Their effects are discussed in this review.

\section{Role of Cell Contacts in Pancreas}

The development of edema during pancreatitis has a putative impact on the course of the disease. It probably interferes with cell-to-cell contacts within the acini. Early studies have demonstrated that dispersion of pancreatic acinar cells results in loss of secretion [3, 4]. The finding that re-establishment of cell-cell contacts promotes basal and stimulated secretion indicates that mechanisms, involving cell-cell interactions, participate in the regulation of secretion in pancreatic acini [5]. Direct cell-to-cell communication is achieved by gap junctions, which are assemblies of transmembrane channels providing a selective pathway for the transfer of ions and signaling molecules. These channels are formed by a multi-gene family of related proteins, referred to as connexins $(\mathrm{Cx})$. Acinar cells are coupled through Cx32- and Cx26-formed gap junction channels [for details, see 6]. To address the question of whether a chronic alteration in the extent of such cell contacts affects the secretory activity in acinar cells in vivo, Chanson et al. [7] used homozygous Cx32-deficient mice $\left(\mathrm{Cx} 32^{-{ }^{-}}\right)$. These animals were generated by targeted homologue recombination [8]. These $\mathrm{Cx} 32^{-/}$ animals showed enhanced serum amylase levels, thereby indicating that a lack of $\mathrm{Cx} 32$ protein in fact alters the function of the exocrine pancreas in vivo. It may well be that the extensive coupling normally observed between acinar cells mediates an inhibitory effect on secretion downregulating the extent of recruitment of acinar cells. Partial loss of gap junctional communication in acini of these animals decreased this inhibition and resulted in an enhanced recruitment of secreting acinar cells. This situation is reflected during acute pancreatitis where a loss of gap junctions is observed. To further explore the possible role of gap junctions during acute pancreatitis in vivo, Frossard et al. [9] studied the course of pancreatitis in mice deficient of connexin 32. These animals showed a deleterious course of acute pancreatitis with increased necrosis, edema, inflammation and decreased apoptosis. However, Lerch et al. [10] demonstrated that the dissociation of adherens junctions and the internalization, relocalization, and reassembly of their major components are likely representing a critical biochemical event at cellcell contacts during edema formation in cerulein-induced pancreatitis in rats.

\section{Zymogen Granule Proteins}

Zymogen granule proteins and Rab proteins are believed to play an important role in regulated exocytosis and disturbances of acinar cell exocytosis may contribute to pancreatitis. Small GTP-binding proteins such as Rab3D are localized on the zymogen granules [11]. In transgenic animals specifically overexpressing Rab3D on zymogen granules [12], a stimulation of permeabilized acini with CCK increased the incorporation of radiolabeled GTP into HA-tagged Rab3D. This indicates that Rab3D is involved crucially in stimulated exocytosis. To further understand the function of Rab3D in this context, Chen et al. [13] generated adenoviral constructs encoding wild-type Rab3D and mutated forms (N135I and T36N deficient in guanine nucleotide binding whereas Q811 was deficient in GTP hydrolysis) and then infected isolated mouse acini. While the expression of Rab3D and the mutant Rab3D Q811 had no effect on amylase secretion, the Rab3D mutants N135I and T36N functioned as dominant negative mutants and inhibited CCK-induced amylase release by $40-50 \%$. Localization of adenoviral expressed Rab proteins showed wild-type Rab3D localized to zymogen granules whereas the two dominant negative mutants did not localize to the granules but primarily to the basolateral cell region. This supported an important role for Rab3D in regulating the terminal steps of acinar exocytosis. Using Western blotting, Ohnishi et al. [14] demonstrated the expression of another Rab protein, Rab4, on zymogen granule membranes. The function in regulated exocytosis was examined by introducing Rab4 peptide and Rab4 antibody into permeabilized acini. Both Rab4 peptide and antibody enhanced calcium-stimulated amylase from streptolysin O-permeabilized acini, suggesting an inhibitory role of Rab4 in exocytosis.

Imamura et al. [15] investigated the function of a novel acinar cell zona pellucida (ZP)1 domain-containing protein (Itmap1). This is an integral membrane-associated protein, prominently expressed in pancreatic acinar cells and localized to zymogen granule membranes. Specific roles in epithelial polarity, granule assembly, and 
mucosal protection have been proposed for these proteins. Still, no functional in vivo data exist so far. To determine the in vivo function, Itmap $1^{-/}$-deficient mice were generated and the effects were investigated in a secretagogue- and diet-induced pancreatitis model. The Itmap1-deficient mice did not present a phenotype under physiological conditions. The granule size and morphology of the acini did not differ from Itmap1 wild-type mice. However, Itmap1-deficient mice showed an impaired activation of trypsinogen but histologically a more severe pancreatitis in both cerulein- and CDE-induced pancreatitis accompanied by increased numbers of apoptotic cells. Western blot analysis revealed no differences in the zymogen granule content between Itmap1-deficient and normal mice. This indicated that the decrease in trypsinogen activity is not due to less trypsinogen content in the zymogen granules.

These data appear controversial but recent data support the hypothesis that trypsinogen activation is not mediated by trypsin itself and that inhibition of trypsin prevents trypsin inactivation and autodegradation $[16,17]$. On the other hand, there is evidence that intrapancreatic activation of trypsinogen plays a critical role in the initiation of acute pancreatitis. In in vitro studies, Saluja et al. [18] demonstrated that intra-acinar cell activation of trypsinogen and acinar cell injury in response to supramaximal secretagogue stimulation was prevented by the cell-permeant cathepsin B inhibitor E64d. Investigations were performed using this cathepsin B inhibitor under in vivo conditions in two independent models of acute experimental pancreatitis, secretagogue-elicited pancreatitis in mice or duct infusion-elicited pancreatitis in rats. They showed a marked reduction of intrapancreatic trypsinogen activation and a substantially reduced severity of pancreatitis in both models [19]. Using pharmacological compounds to inhibit proteases or kinases always raises concerns regarding the specificity of the observed effects. Therefore, investigating the specific role of cathepsin B in pancreatitis, Halangk et al. [20] used mice with a genetic deletion of cathepsin B. They found that deletion of cathepsin B was associated with an approximately 50\% reduction in intrapancreatic trypsinogen activation and in the severity of pancreatitis. These effects are less pronounced as effects with the antagonist reported by van Acker et al. [19]. It rather likely indicates that additional proteases other than cathepsin B are involved in intrapancreatic trypsinogen activation. Nonetheless, selective cathepsin B inhibitors might be of therapeutic potential.

\section{Heat-Shock Proteins}

Exposure of organisms to an initial sublethal stress leads to the synthesis of heat-shock proteins (Hsps) and confers protection against a subsequent more severe stress. Hsps are highly conserved, exist in all organisms, and are believed to act in part as molecular chaperones. In the pancreas, the possible roles for Hsps in physiologic and pathophysiologic processes have previously been reviewed [for details, see 21]. The pattern of individual pancreatic Hsps induced by cell stress is dependent on the type of applied stress (thermal, water immersion, etc.), but the overall protective effect against experimental pancreatitis is consistent. Bhagat et al. [22] reported recently that applying antisense oligonucleotides of $\mathrm{Hsp} 70$ before induction of thermal stress inhibited the upregulated expression of Hsp70 in response to hyperthermia while the upregulated expression of $\mathrm{Hsp} 27$ in response to hyperthermia remained unaffected. In addition, rats exposed to thermal stress were protected in response to cerulein, but that protection was lost when animals were given the antisense oligonucleotides before thermal stress. These data indicate that Hsp70 plays a critical role in mediating protection against pancreatitis gained by thermal stress [22]. Furthermore, overexpression of Hsp70 in the pancreas of transgenic mice ameliorates acute pancreatitis and supports the concept of Hsp70 being protective against pancreatitis [23]. The significance of the small Hsp27 has so far received little attention in most studies but it has been reported to increase during arginine- and cerulein-induced pancreatitis [24], putatively signaling a mechanism of self-protection [25].

Hsp27 is a phosphorylation-dependent regulator of actin polymerization. CCK stimulates pancreatic Hsp27 phosphorylation both in vivo and in vitro $[24,26]$. Therefore, Hsp27 may also participate in the regulation of the actin cytoskeleton during cerulein-induced acute pancreatitis. Previously, we showed that overexpression of human Hsp27 and a mutated form (huHsp27-3D) which mimics phosphorylation protects the cell architecture and F-actin cytoskeleton changes induced by stimulation with supramaximal concentrations of $\mathrm{CCK}$ in $\mathrm{CHO}$ cells, whereas overexpression of a non-phosphorylatable form of Hsp27 (huHsp27-3A) failed to achieve such a favorable action [27].

Therefore, investigating the effects of $\mathrm{Hsp} 27$ in vivo utilizing a model of secretagogue-induced pancreatitis, we generated transgenic mice overexpressing human Hsp27 or its mutant forms (huHsp27-3A and huHsp27$3 \mathrm{D})$ in exocrine pancreatic acini using a CMV promoter. 
In our study, we provide evidence that overexpression of a single heat-shock protein, Hsp27, in the pancreas of transgenic mice confers resistance against cerulein-induced pancreatitis in vivo. Transgenic mice expressing huHsp27 or the mutant form huHsp27-3D which mimics phosphorylation of Hsp27 showed a reduced activation of intrapancreatic trypsinogen, reduced serum lipase and amylase levels. Furthermore, less intracellular damage and inflammation occurred. A grossly preserved actin cytoskeleton was seen. No protective effects were found in animals expressing the huHsp27-3A mutant. However, the exact molecular protection mechanism of Hsp27 is still unclear but clearly it exerts its effect by preserving the F-actin microfilaments and inhibiting actin redistribution [28].

\section{Cytokines and Pancreatitis in Transgenic Animal Models}

Inflammatory effects play an important role in the pathogenesis of pancreatitis although the exact mechanisms that cause the inflammatory and necrotizing process are only beginning to emerge. Cytokines mediate deleterious events in the pancreas as well as in associated systems resulting in complications like lung injury and multiple organ dysfunction syndrome (MODS). Current concepts on cytokines and acute pancreatitis are reviewed in Brady et al. [29] and Schmid and Adler [30].

A candidate mediator of the inflammatory response in acute pancreatitis is the transcription factor nuclear factor- $\kappa \mathrm{B}(\mathrm{NF} \kappa \mathrm{B})$. It has been found that activation of $\mathrm{NF} \kappa \mathrm{B}$ occurs early within acinar cells in the course of acute experimental pancreatitis $[31,32]$ and is correlated with the expression of cytokines and chemokines [33, 34]. However, the specific role of $\mathrm{NF \kappa B}$ during onset of pancreatitis (i.e., proinflammatory or protective) is currently unknown and controversial [35]. Details have recently been reviewed by Algül et al. [36]. To further explore the role of NFкB, Chen et al. [37] used adenoviral-mediated transfer in isolated acinar cells. Administration of Adp65 caused activation of NFKB and the expression of NFKB target genes. It increased the infiltration of neutrophils to the pancreas and lung and caused damage to pancreatic acinar cells. Co-administration of Adp65 with the inhibitory subunit I $\mathrm{B}-\alpha$ reduced the level of NFKB activation and the inflammatory response. These data strongly suggest that activation of NFKB in pancreatic acinar cells is a major proinflammatory factor in acute pancreatitis.

Transgenic Animal Models in Acute Pancreatitis
Several studies were performed focusing on a variety of cytokines: An overview of genetically altered mice and the effects on cytokines in acute experimental pancreatitis models are shown in table 1.

Interferon- $\gamma($ IFN- $\gamma$ ) expression in the pancreas causes islet cell destruction, hyperglycemia and initiates inflammation. Overexpression of IFN- $\gamma$ in mice leads to a transient upregulation of EGF, TGF- $\alpha$ and the EGF receptor. In addition, transgenic IFN- $\gamma$ mice have the unique capacity to regenerate from proliferating ducts. These cytokines are probably involved in mediating the regenerative changes leading to fibrosis that resemble those observed in chronic pancreatitis [38]. In a study investigating the patterns of proliferation and differentiation of pancreatic tissue, Gu et al. [39] show that treatment of IFN- $\gamma$ mice with an IFN- $\gamma$ antibody not only reduces elevated blood glucose levels but also lowers the mitotic index of pancreatic ducts and islet cells.

Transforming growth factors such as TGF- $\beta$ play a role in differentiation and tissue repair [40]. Altered expression of this cytokine is found in a variety of pathological stages like autoimmune diseases, carcinogenesis, fibrosis and chronic inflammation [41-43]. Expression of TGF- $\beta$ is detected in normal human pancreas. TGF- $\alpha$ overexpression is found in the pancreas of patients with chronic pancreatitis [44]. The influence of TGF- $\alpha$ on fibrosis was already mentioned by Bockman and Merlino [45] in 1992, reporting that TGF- $\alpha$ transgenic mice undergo marked fibrosis. The formation of duct-like tubular complexes in TGF- $\alpha$ overexpressing mice is associated with increased TFF peptide (formerly called trefoil factors or P-domain peptide) expression [46]. A double transgenic breading for TGF- $\alpha$ and TGF- $\beta_{1}$ leads to a dramatic decrease of $\beta$-cells and the development of diabetes mellitus within 4 months [47]. TGF- $\beta_{1}$ overexpression alone leads to a progressive accumulation of extracellular matrix [48], ultimately resulting in massive fibrosis [47]. This process is accompanied by cellular infiltrates comprising macrophages and neutrophils. It inhibits the proliferation of acinar cells [49]. Opposed to the deleterious effects of TGF- $\beta_{1}$ overexpression, Hahm et al. [43] showed that TGF- $\beta$ is essential for normal immune homeostasis and protective against autoimmunity. Impaired TGF- $\beta$ signaling contributes to autoimmune pancreatitis: Studies in mice overexpressing a dominant negative mutant from of the TGF- $\beta$ receptor in the pancreas show an increase in MHC class 2 molecules, increased susceptibility to cerulein-induced pancreatitis displaying $\mathrm{T}$ - and $\mathrm{B}-\mathrm{cell}$ hyperactivation, IgG-type autoantibodies against acinar cells and IgM autoantibodies against pancreatic ductal 
epithelial cells. Mice overexpressing a dominant negative mutant form of the TGF- $\beta$ receptor also display a loss of growth inhibitory and gene induction responses, indicating that TGF- $\beta$ negatively controls acinar cell growth and is vital for the maintenance of a differentiated acinar phenotype in vivo [50].

IL-1 is a proinflammatory cytokine predominantly released from macrophages causing fever, hypotension and anorexia. Clinical symptoms after IL-1 administration resemble those after TNF- $\alpha$ treatment and are difficult to discriminate. The effects are probably due to the activation of neutrophils and the increase of adhesion molecules on leukocytes as well as endothelial cells. Norman et al. [51] utilized a homozygous knockout of the ICE gene which is necessary to process pro-IL-1 intracellulary. In a model of choline-deficient, ethionine-supplemented diet, the lack of IL-1 production increases survival from 24 to $80 \%$. Interestingly, IL-1 mRNA production is not altered in these knockout mice. Another study of this group using transgenic mice with an IL-1 receptor deletion even reports $30-50 \%$ greater levels of IL-1 mRNA in knockouts as compared to wild-type animals [52]. A negative feedback loop between the IL-1 receptor and gene expression is suggested. In addition, the genetic absence of the receptor in IL-1 receptor knockout mice as well as a pharmacologic blockade with a recombinant receptor antagonist resulted in an attenuated pancreatitis and lower IL-6 levels [53].

A wide range of cells including macrophages/monocytes, endothelial cells, fibroblasts and smooth muscle cells, expresses IL-6. Release of IL-6 is also observed after stimulation with IL- 1 and TNF- $\alpha$. This cytokine causes pyrexia, stimulates the production and release of acute phase proteins with levels of IL- 6 peaking $24 \mathrm{~h}$ before those of acute phase proteins. IL-6 is elevated in patients with acute pancreatitis and levels correlate with the severity of the disease [54]. In animal studies, the effects of IL-6 are controversial: In transgenic mice expressing human IL-6, the pancreatic wet weight induced by cerulein was significantly higher compared with wild-type mice, but pretreatment with a specific anti-IL-6 receptor antibody did not reduce interstitial edema. When cerulein was administered with LPS, the pancreatic wet weight increased much more as compared to pancreatitis after cerulein alone. Pretreatment with the anti-IL-6 receptor antibody reduced the pancreatic edema only in humanIL-6 transgenic mice. The authors of this study concluded that anticytokine antibodies might be effective in improving acute pancreatitis [55].
On the other hand, studying the effects of endogenous IL-6 in pancreatitis, Cuzzocrea et al. [56] utilized IL-6 knockout mice in a model of cerulein-induced pancreatitis. They showed that such knockout mice have higher plasma levels of TNF- $\alpha$ and IL- $1 \beta$, a higher degree of oxidative and nitrosative tissue damage, more severe tissue injury and an increased mortality rate as wild-type animals. The authors suggested that IL-6 might in fact be an anti-inflammatory cytokine. It is conceivable that gene deletion of IL- 6 results in an upregulation of TNF- $\alpha$ as a compensatory mechanism and therefore it is an important proinflammatory cytokine.

IL-10 is a potent anti-inflammatory cytokine, which inhibits inflammatory cytokine release from many tissues. Hepatic cytokine release from Kupffer cells (KC) is an important source of inflammatory cytokines and thus may contribute to lung damage in acute pancreatitis. To investigate the specific role of IL-10, knockout mice were generated and pancreatitis was induced with or without blockade of KC activity. For induction of pancreatitis, animals were fed a choline-deficient, ethionine-supplemented diet and gadolinium chloride to inhibit $\mathrm{KC}$ activity. $\mathrm{KC}$ blockade has neither an effect on the degree of edema in knockout mice, nor on neutrophil infiltration and histological lung changes. All effects are more severe in knockout animals as compared to $\mathrm{C} 57 \mathrm{BL} / 6 \mathrm{~J}$ mice proving that IL-10 is important in reducing lung injury after induction of acute pancreatitis. Also, KC-derived cytokines seem to be of minor importance as compared to those derived from other tissues [57].

New approaches were undertaken to elucidate the intracellular pathways of cytokine action in pancreatitis. One hypothesis states that TNF- $\alpha$ and IL- 6 are regulated via the $\mathrm{p} 38 / \mathrm{MK} 2$ pathway. Thus, knockout or inhibition of p38 or MK2 would result in lower levels of those cytokines and consequently in a less severe pancreatitis. We studied this hypothesis in MK2 knockout mice using the model of cerulein-induced pancreatitis. The knockout mice showed drastically reduced IL- 6 and TNF- $\alpha$ serum levels and a marked histological protection with lacking inflammatory cells against pancreatitis as compared to control animals. These data support the concept that reduction of IL- 6 and TNF- $\alpha$ levels ameliorates secretagogue-induced pancreatitis and suggest that the p38 and MAPKAP-2 pathway is hereby essential [58].

Not only cytokines, but also their receptors play a pivotal role in pancreatitis. To assess the independent in vivo activities of the $\mathrm{p} 75 \mathrm{TNF}$ receptor, transgenic mice were generated expressing this receptor constitutively with disease-relevant levels compared to wild-type human 
p75TNF-R. Studies with such mice revealed that activation of this receptor triggers a severe multi-organ inflammatory syndrome. Similarly to the prolonged NFKB activation observed in peripheral blood mononuclear cells (PBMC) from human septic patients and shown to cause pathology in models of endotoxemia, NFKB-binding activity was found constitutively increased in PBMC from hup75TNF-R transgenic mice suggesting an in vivo role for the p75TNF-R in triggering this pathogenic cascade. Interestingly, the severity of pathologic changes developing in the human $\mathrm{p} 75 \mathrm{TNF}-\mathrm{R}$ transgenic mice corresponded to the levels of soluble $\mathrm{p} 75 \mathrm{TNF}-\mathrm{R}$ measured in the sera of these animals. This reflected the quantitative correlation between levels of human soluble $\mathrm{p} 75$ TNF-R production and severity of human disease. Remarkably, the pathogenic potential of this receptor was even shown in the absence of its known ligands, TNF or lymphotoxin- $\alpha$ and independently of the presence of the p55TNF-R. These results established an independent role for induced production of the p75TNF-R in the pathogenesis of inflammation and suggest that antagonizing the receptor function may generally be beneficial in inflammation [59].

\section{Other Proinflammatory Systems}

Other intra- and extracellular mediators have been discovered in addition to cytokines altering the course of pancreatitis. In a study with intercellular adhesion molecule 1 (ICAM-1) knockout animals, Frossard et al. [60] discovered that lung injury as well as pancreatic injury is ameliorated but not abolished. Interestingly, a combination of this gene knockout with neutrophil depletion left the severity of inflammation in both organs grossly unaltered. On the other hand, it was hypothesized that neutrophils recruited to the pancreas during pancreatitis may contribute to intrapancreatic activation of digestive enzymes. To test this, Gukovskaya et al. [61] used mice deficient in either nicontinamide adenine dinucleotide phosphate(NADPH) oxidase or myeloperoxidase(MPO). Mice deficient in NADPH oxidase showed attenuation of the cerulein-induced trypsin activation, but those deficient in MPO did not. Biochemical measurements revealed that the NADPH oxidase resides in neutrophils and not in pancreatic acinar tissue. This indicates a role for neutrophils infiltrating the pancreas with pathologic activation of digestive enzymes. In addition, the products of NADPH oxidase probably mediated the effects.

Transgenic Animal Models in Acute Pancreatitis
The activation and trafficking of inflammatory cells involves chemokines. Complement, neutrophils and TNF- $\alpha$ are involved in the manifestation of pancreatitisassociated lung injury. Using a gene-targeting approach, Gerard et al. [62] investigated the role of chemokines in pancreatitis and pancreatitis-associated lung injury. Deletion of the $\beta$-chemokine receptor CCR 1 in mice resulted in reduced pancreatic MPO activity while the severity of the pancreatitis was unaffected in the pancreas. However, CCR1-deficient mice showed a marked protection from pulmonary inflammation secondary to acute pancreatitis. The protection was accompanied with decreased levels of TNF- $\alpha$ in a temporal sequence. These results indicate that activation of the CCR 1 receptor is an early event in the systemic inflammatory response.

Cyclooxygenase-2 (Cox-2) plays an important role in inflammation and catalyzes the rate-limiting step in prostaglandin synthesis. More recently, two groups showed independently that inhibition of Cox-2 using pharmacological compounds or mice deficient for Cox-2 ameliorates the severity of pancreatitis and pancreatitis-associated lung injury [63, 64]. In addition, Ethridge et al. [64] demonstrated that these effects are specific for COX-2 while genetic deletion of the Cox-1 gene had no protective effect.

Beside Cox-2 as a known proinflammatory enzyme, the neurokin substance $\mathrm{P}$ has been shown to impact on a variety of inflammatory processes. Bhatia et al. [65] showed increased levels of substance $P$ and enhanced expression of the corresponding neurokinin-1 receptor (NK1R) during cerulein-induced pancreatitis. To further evaluate the role of substance $\mathrm{P}$, these groups generated mice that genetically lacked NK1R and induced pancreatitis by administration of cerulein. In these mice, pancreatitis and pancreatitis-associated lung injury were attenuated significantly compared to wild-type NK1R mice. This indicates that substance P acts via the NK1R receptor and plays a proinflammatory role in regulating the severity of acute pancreatitis.

Most recently, further neuropeptides have been discovered to enhance pancreatitis in mice. Deletion of the preprotachykinin-A gene, a precursor of substance $\mathrm{P}$ and neurokinin-A, completely protects against pancreatitisassociated lung injury and partially protects against local pancreatic damage in mice [66].

Complement activation seems also to play a crucial role in the process of inflammation. Complement activation involves subsequent proteolytic events generating fragments with individual signaling properties. $\mathrm{C} 5 \mathrm{a}$ is the product of proteolysis of $\mathrm{C} 5$ and is considered an anaphy- 
lotoxin. Bhatia et al. [67] studied animals lacking either C5 or C5a receptors. These animals exhibit a greater severity of pancreatitis and associated lung injury as compared to wild-type animals indicating that $\mathrm{C} 5$ has an antiinflammatory effect in pancreatitis.

There are several known proteins which influence the inflammatory cascade of acute pancreatitis. The role of $\mathrm{T}$ lymphocytes in the pathogenesis of acute experimental pancreatitis is only poorly characterized. To further shed light onto this, Demols et al. [68] used nude mice and in vivo $\mathrm{CD}^{+}$or $\mathrm{CD}^{+}$T-cell-depleted mice. Nude mice showed a significant reduction in the severity of acute pancreatitis (approximately 3-fold) compared to wildtype controls and $\mathrm{T}$ lymphocytes transferred to nude mice restored the severity of the pancreatitis. Among T lymphocytes, $\mathrm{CD} 4^{+} \mathrm{T}$ cells play a major role because in vivo depletion by anti-CD4Mab administration to wild-type mice reduces the severity of pancreatitis to a similar extent as observed in nude mice, whereas $\mathrm{CD} 8^{+}$depletion does not affect the course of acute pancreatitis.

The specific role of phospholipase $\mathrm{A}_{2}$ in acute pancreatitis is still unclear. To further resolve its role in the pathogenesis of acute pancreatitis, Mayer et al. [69] generated mice expressing human group IIA phospholipase $\mathrm{A}_{2}$ and examined the severity of pancreatitis compared to $\mathrm{C} 57 / \mathrm{bl}$ (wild-type) mice. After pancreatitis induction with a choline-deficient, ethionine-supplemented diet, no differences in the severity of pancreatitis were found. This study argues against group IIA phospholipase $A_{2}$ as an important factor for the severity of experimental pancreatitis.

In conclusion, the discussed data demonstrate that with the help of transgenic animal models and other molecular approaches, new insights in the pathophysiology of acute pancreatitis have been gained. Transgenic models are essential to elucidate pathophysiological processes in the development and maintenance of pancreatitis. Those transgenic approaches range from structural proteins over zymogen granule proteins like the GTPase Rab3D and Itmap1 to proteases like cathepsin B as well as Hsps, cytokines, and MAP kinases. These data imply new therapeutic strategies for patients at risk with acute pancreatitis, for example after ERCP, with anticytokine antibodies or protease inhibitors. In addition, other pharmacological tools like specific kinase inhibitors and antibodies appear promising in the treatment and prevention of pancreatitis.

Despite all the advantages coming from transgenic animal models, the transfer to the clinical situations is doubtful.
Interactions between proteins, genes and overlapping effects remain unconsidered in transgenic animals. Especially in inflammatory processes the cascades of activation are probably more complex. One transgene might be up- or downregulating or simply modulate several processes at the same time. Inflammatory actions induce events in which not just one factor activates the subsequent downstream protein. Rather, one factor is often regulated by many upstream elements, sometimes only through interaction of several factors at the same time. One transgene does not necessarily inhibit or induce the next downstream mediator on its own. Therefore, transgenic models reduce processes often to a hypothetical linear cascade that does not mirror the complex regulatory pathways in inflammation.

It will still be a great challenge to understand the complex interactions between proteins and genes leading to pancreatitis. The transgenic animals of the next generation would ideally take those interactions into consideration and double transgenes might help in understanding the underlying processes. With the Cre/loxP system a new transgenic tool is available with the ability both to overexpress proteins in specific tissues and to eliminate their expression in selected sites. Cre is the product of the cyclation recombination gene of bacteriophage P1. This enzyme recognizes loxP (locus of $\mathrm{X}$-over of $\mathrm{P} 1$ ) and excises the genetic region flanked by loxP. By specific placement of loxP sites into the intron of a target gene, a functionally 'normal' mouse, yet carrying the loxP sites, is created. By mating this mouse with another mouse, which expresses Cre under a specifically designed promoter (tissue specific and or inducible), the target gene is activated in vivo.

As compared to conventional knockout mouse models, the Cre/loxP system represents a model of conditional mutagenesis with the novel advantage of an organ- or cell-specific activation or ablation of a target gene. When designed with an inducible promoter, the gene of interest can be expressed in a timely controlled mode, too. This technology renders new and promising progress in the elucidation of the pathophysiology of acute pancreatitis.

In the field of pancreatic cancer, first research results have been reported by Grippo et al. [70] with Cre expression under an elastase promoter-activating TNF- $\alpha$ expression and by Aguirre et al. [71] studying a pancreas-specific Cre-mediated activation of a mutant K-ras allele and the deletion of the tumor suppressor allele Ink4a/Arf.

The Cre/loxP system has so far not been established widely to clarify the development and perpetuation of acute pancreatitis. There is certainly need for these inducible gene-targeting studies to clarify the pathophysiology 
of acute pancreatitis, for example by creating an inducible $\mathrm{NF \kappa B}$ model to further evaluate the role of NFKB in this disease. Even though animal models are an essential step in the translational process of research, only clinical studies will ultimately verify the importance of the results.

Because of space limitations, this review cannot claim completeness of all transgenic animal studies in experimental pancreatitis. However, it points out the major results in this field.

\section{Acknowledgments}

This work was supported by Deutsche Forschungsgesellschaft grant SCHA 766/3-1 (to C.S.) and Friedrich-Baur-Stiftung grant 065/04 (to C.S.).

\section{References}

1 Natori S, King A, Hellwig A, Weiss U, Iguchi $\mathrm{H}$, Tsuchiya B, Kameya T, Takayanagi R, Nawata H, Huttner WB: Chromogranin B (secretogranin I), a neuroendocrine-regulated secretory protein, is sorted to exocrine secretory granules in transgenic mice. EMBO J 1998;17: 3277-3289.

2 Galli-Taliadoros LA, Sedgwick JD, Wood SA, Korner H: Gene knock-out technology: A methodological overview for the interested novice. J Immunol Methods 1995;181:1-15.

3 Amsterdam A, Jamieson JD: Studies on dispersed pancreatic exocrine cells. II. Functional characteristics of separated cells. J Cell Biol 1974;63:1057-1073.

4 Gardner JD, Jackson MJ: Regulation of amylase release from dispersed pancreatic acinar cells. J Physiol 1977;270:439-454.

5 Bosco D, Soriano JV, Chanson M, Meda P: Heterogeneity and contact-dependent regulation of amylase release by individual acinar cells. J Cell Physiol 1994;160:378-388.

6 Meda P: Gap junction involvement in secretion: The pancreas experience. Clin Exp Pharmacol Physiol 1996;23:1053-1057.

7 Chanson M, Fanjul M, Bosco D, Nelles E, Suter S, Willecke K, Meda P: Enhanced secretion of amylase from exocrine pancreas of connexin 32-deficient mice. J Cell Biol 1998;141: 1267-1275.

8 Nelles E, Butzler C, Jung D, Temme A, Gabriel HD, Dahl U, Traub O, Stumpel F, Jungermann K, Zielasek J, Toyka KV, Dermietzel R, Willecke K: Defective propagation of signals generated by sympathetic nerve stimulation in the liver of connexin 32-deficient mice. Proc Natl Acad Sci USA 1996;93:9565-9570.

9 Frossard JL, Rubbia B, Wallig M, Benathan M, Ott T, Morel P, Hadengue A, Suter S, Willecke $\mathrm{K}$, Chanson M: Severe acute pancreatitis and reduced acinar cell apoptosis in the exocrine pancreas of mice deficient for the Cx32 gene. Gastroenterology 2003;124:481-493.

10 Lerch MM, Lutz MP, Weidenbach H, MullerPillasch F, Gress TM, Leser J, Adler G: Dissociation and reassembly of adherens junctions during experimental acute pancreatitis. Gastroenterology 1997;113:1355-1366.
11 Ohnishi H, Ernst SA, Wys N, McNiven M, Williams JA: Rab3D localizes to zymogen granules in rat pancreatic acini and other exocrine glands. Am J Physiol 1996;271:G531-G538.

12 Ohnishi H, Samuelson LC, Yule DI, Ernst SA Williams JA: Overexpression of Rab3D enhances regulated amylase secretion from pancreatic acini of transgenic mice. J Clin Invest 1997; 100:3044-3052.

13 Chen X, Edwards JAS, Logsdon CD, Ernst SA, Williams JA: Dominant negative Rab3D inhibits amylase release from mouse pancreatic acini. J Biol Chem 2002;277:18002-18009.

14 Ohnishi H, Mine T, Shibata H, Ueda N, Tsuchida T, Fujita T: Involvement of Rab4 in regulated exocytosis of rat pancreatic acini. Gastroenterology 1999;116:943-952.

15 Imamura T, Asada M, Vogt SK, Rudnick DA, Lowe ME, Muglia LJ: Protection from pancreatitis by the zymogen granule membrane protein integral membrane-associated protein-1. J Biol Chem 2002;277:50725-50733.

16 Lerch MM, Gorelick FS: Early trypsinogen activation in acute pancreatitis. Med Clin North Am 2000;84:549-563.

17 Halangk W, Kruger B, Ruthenburger M, Sturzebecher J, Albrecht E, Lippert H, Lerch MM: Trypsin activity is not involved in premature, intrapancreatic trypsinogen activation. Am J Physiol 2002;282:G367-G374.

18 Saluja A, Donovan E, Yamanaka K, Yamaguchi Y, Hofbauer B, Steer M: Cerulein-induced in vitro activation of trypsinogen in rat pancreatic acini is mediated by cathepsin B. Gastroenterology 1997;113:304-310.

19 Van Acker GJD, Saluja AK, Bhagat L, Singh VP, Song AM, Steer ML: Cathepsin B inhibition prevents trypsinogen activation and reduces pancreatitis severity. Am J Physiol 2002; 283:G794-G800.

20 Halangk W, Lerch MM, Brandt-Nedelev B, Roth W, Ruthenbuerger M, Reinheckel T, Domschke W, Lippert H, Peters C, Deussing $\mathrm{J}$ : Role of cathepsin B in intracellular trypsinogen activation and the onset of acute pancreatitis. J Clin Invest 2000;106:773-781.

21 Schäfer C, Williams JA: Stress kinases and heat shock proteins in the pancreas: Possible roles in normal function and disease. J Gastroenterol 2000;35:1-9.
22 Bhagat L, Singh VP, Song AM, van Acker GJ, Agrawal S, Steer ML, Saluja AK: Thermal stress-induced Hsp70 mediates protection against intrapancreatic trypsinogen activation and acute pancreatitis in rats. Gastroenterology 2002;122:156-165.

23 Bhagat L, Dawra R, Dhaulakhandi D, Ku YS, Sharif R, Garg L, Saluja A: Overexpression of heat shock protein 70 protects against secretagogue-induced pancreatitis. Pancreas 2003; 27:371.

24 Tashiro M, Schäfer C, Yao H, Ernst SA, Williams JA: Arginine-induced acute pancreatitis alters the actin cytoskeleton and increases heat shock protein expression in rat pancreatic acinar cells. Gut 2001;49:241-250.

25 Ethridge RT, Ehlers RA, Hellmich MR, Rajaraman S, Evers BM: Acute pancreatitis results in induction of heat shock proteins 70 and 27 and heat shock factor-1. Pancreas 2000;21: 248-256.

26 Schäfer C, Ross SE, Bragado MJ, Groblewski GE, Ernst SA, Williams JA: A role for the p38 mitogen-activated protein kinase/Hsp27 pathway in cholecystokinin-induced changes in the actin cytoskeleton in rat pancreatic acini. J Biol Chem 1998;273:24173-24180.

27 Schäfer C, Clapp P, Welsh MJ, Benndorf R, Williams JA: Hsp27 expression regulates CCK-induced changes of the actin cytoskeleton in CHO-CCK-A cells. Am J Physiol 1999; 277:C1032-C1043.

28 Kubisch C, DiMagno MJ, Tietz AB, Welsh MJ, Ernst SA, Brandt-Nedelev B, Diebold J, Wagner ACC, Göke B, Williams JA, Schäfer C: Overexpression of heat shock protein Hsp27 protects against cerulein-induced pancreatitis. Gastroenterology 2004;127:275-286.

29 Brady M, Christmas S, Sutton R, Neoptolemos J, Slavin J: Cytokines and acute pancreatitis. Baillieres Best Pract Res Clin Gastroenterol 1999;13:265-289.

30 Schmid RM, Adler G: Cytokines in acute pancreatitis - New pathophysiological concepts evolve. Eur J Gastroenterol Hepatol 1999; 11: 125-127.

31 Gukovsky I, Gukovskaya AS, Blinman TA, Zaninovic V, Pandol SJ: Early NF-кB activation is associated with hormone-induced pancreatitis. Am J Physiol 1998;275:G1402-G1414. 
32 Steinle A, Weidenbach H, Wagner M, Adler G, Schmid R: NF-кB/Rel activation in cerulein pancreatitis. Gastroenterology 1999;116:420430.

33 Gukovskaya AS, Gukovsky I, Zaninovic V, Song M, Sandoval D, Gukovsky S, Pandol SJ: Pancreatic acinar cells produce, release, and respond to tumor necrosis factor- $\alpha$. Role in regulating cell death and pancreatitis. J Clin Invest 1997; 100:1853-1862.

34 Grady T, Liang P, Ernst S, Logsdon C: Chemokine gene expression in rat pancreatic acinar cells is an early event associated with acute pancreatitis. Gastroenterology 1997; 113: 1966-1975.

35 Grisham M: NF-кB activation in acute pancreatitis: Protective, detrimental, or inconsequential? Gastroenterology 1999;116:489-492.

36 Algul H, Tando Y, Schneider G, Weidenbach H, Adler G, Schmid RM: Acute experimental pancreatitis and NF-кB/Rel activation. Pancreatology 2002;2:503-509.

37 Chen X, Ji B, Han B, Ernst SA, Simeone D, Logsdon CD: NF- $\mathrm{KB}$ activation in pancreas induces pancreatic and systemic inflammatory response. Gastroenterology 2002;122:448457.

38 Arnush M, Gu D, Baugh C, Sawyer SP, Mroczkowski B, Krahl T, Sarvetnick N: Growth factors in the regenerating pancreas of interferon$\gamma$ transgenic mice. Lab Invest 1996;74: 985-990.

39 Gu D, Molony L, Krahl T, Sarvetnick N: Treatment of IFN- $\gamma$ transgenic mice with anti-IFN$\gamma$ reveals the remodeling capacity of the adult pancreas. Diabetes 1995;44:1161-1164.

40 Massague J, Weis-Garcia F: Serine/threonine kinase receptors: Mediators of transforming growth factor- $\beta$ family signals. Cancer Surv 1996;27:41-64.

41 Roberts AB, Sporn MB: Physiological actions and clinical applications of transforming growth factor- $\beta$. Growth Factors 1993;8:1-9.

42 Markowitz SD, Roberts AB: Tumor suppressor activity of the TGF- $\beta$ pathway in human cancers. Cytokine Growth Factor Rev 1996; 7: 93-102.

43 Hahm KB, Im YH, Lee C, Parks WT, Bang YJ, Green JE, Kim SJ: Loss of TGF- $\beta$ signaling contributes to autoimmune pancreatitis. J Clin Invest 2000; 105:1057-1065.

44 Korc M, Friess H, Yamanaka Y, Kobrin MS, Büchler M, Beger HG: Chronic pancreatitis is associated with increased concentrations of epidermal growth factor receptor, transforming growth factor- $\alpha$, and phospholipase C- $\gamma$. Gut 1994;35:1468-1473.

45 Bockman DE, Merlino G: Cytological changes in the pancreas of transgenic mice overexpressing transforming growth factor- $\alpha$. Gastroenterology 1992;103:1883-1892.

46 Ebert MP, Hoffmann J, Haeckel C, Rutkowski K, Schmid RM, Wagner M, Adler G, Schulz HU, Roessner A, Hoffmann W, Malfertheiner $P$ : Induction of TFF1 gene expression in pancreas overexpressing transforming growth factor- $\alpha$. Gut 1999;45:105-111.
47 Sanvito F, Nichols A, Herrera PL, Huarte J, Wohlwend A, Vassalli JD, Orci L: TGF- $\beta_{1}$ overexpression in murine pancreas induces chronic pancreatitis and, together with TNF- $\alpha$, triggers insulin-dependent diabetes. Biochem Biophys Res Commun 1995;217:1279-1286.

48 Vogelmann R, Ruf D, Wagner M, Adler G, Menke A: Effects of fibrogenic mediators on the development of pancreatic fibrosis in a TGF- $\beta_{1}$ transgenic mouse model. Am J Physiol 2001;280:G164-G172.

49 Lee MS, Gu D, Feng L, Curriden S, Arnush M, Krahl T, Gurushanthaiah D, Wilson C, Loskutoff DL, Fox H: Accumulation of extracellular matrix and developmental dysregulation in the pancreas by transgenic production of transforming growth factor- $\beta_{1}$. Am J Pathol 1995; 147:42-52.

50 Bottinger EP, Jakubczak JL, Roberts IS, Mumy M, Hemmati P, Bagnall K, Merlino G, Wakefield LM: Expression of a dominant-negative mutant TGF- $\beta$ type II receptor in transgenic mice reveals essential roles for TGF- $\beta$ in regulation of growth and differentiation in the exocrine pancreas. EMBO J 1997; 16:2621-2633.

51 Norman J, Yang J, Fink G, Carter G, Ku G, Denham W, Livingston D: Severity and mortality of experimental pancreatitis are dependent on interleukin-1 converting enzyme. J Interferon Cytokine Res 1997;17:113-118.

52 Norman JG, Fink GW, Sexton C, Carter G: Transgenic animals demonstrate a role for the IL-1 receptor in regulating IL-1 $\beta$ gene expression at steady-state and during the systemic stress induced by acute pancreatitis. J Surg Res 1996:63:231-236.

53 Norman JG, Fink G, Franz M, Guffey J, Carter G, Davison B, Sexton C, Glaccum M: Active interleukin-1 receptor required for maximal progression of acute pancreatitis. Ann Surg 1996;223:163-169.

54 Leser HG, Gross V, Scheibenbogen C, Heinisch A, Salm R, Lausen M, Ruckauer K, Andreesen R, Farthmann EH, Scholmerich J: Elevation of serum interleukin- 6 concentration precedes acute-phase response and reflects severity in acute pancreatitis. Gastroenterology 1991;101:782-785.

55 Suzuki S, Miyasaka K, Jimi A, Funakoshi A: Induction of acute pancreatitis by cerulein in human IL-6 gene transgenic mice. Pancreas 2000;21:86-92.

56 Cuzzocrea S, Mazzon E, Dugo L, Centorrino T, Ciccolo A, McDonald MC, de Sarro A, Caputi AP, Thiemermann C: Absence of endogenous interleukin-6 enhances the inflammatory response during acute pancreatitis induced by cerulein in mice. Cytokine 2002;18:274285.

57 Gloor B, Todd KE, Lane JS, Rigberg DA, Reber HA: Mechanism of increased lung injury after acute pancreatitis in IL-10 knockout mice. J Surg Res 1998;80:110-114.

58 Tietz AB, Wagner ACC, Gaestel M, Göke B, Schäfer C: Gene deletion of MAPKAPK-2 inhibits TNF- $\alpha$ and protects against cerulein-induced pancreatitis. Gastroenterology 2004, 126(suppl 2).
59 Douni E, Kollias G: A critical role of the p75 tumor necrosis factor receptor ( $\mathrm{p} 75 \mathrm{TNF}-\mathrm{R}$ ) in organ inflammation independent of TNF, lymphotoxin- $\alpha$, or the p55TNF-R. J Exp Med 1998;188:1343-1352.

60 Frossard JL, Saluja A, Bhagat L, Lee HS, Bhatia M, Hofbauer B, Steer ML: The role of intercellular adhesion molecule-1 and neutrophils in acute pancreatitis and pancreatitis-associated lung injury. Gastroenterology 1999;116:694701

61 Gukovskaya AS, Vaquero E, Zaninovic V, Gorelick FS, Lusis AJ, Brennan ML, Holland S, Pandol SJ: Neutrophils and NADPH oxidase mediate intrapancreatic trypsin activation in murine experimental acute pancreatitis. Gastroenterology 2002;122:974-984.

62 Gerard C, Frossard JL, Bhatia M, Saluja A, Gerard NP, Lu B, Steer M: Targeted disruption of the $\beta$-chemokine receptor CCR 1 protects against pancreatitis-associated lung injury. $\mathrm{J}$ Clin Invest 1997;100:2022-2027.

63 Song AM, Bhagat L, Singh VP, Van Acker GGD, Steer ML, Saluja AK: Inhibition of cyclooxygenase-2 ameliorates the severity of pancreatitis and associated lung injury. Am J Physiol 2002;283:G1166-G1174.

64 Ethridge R, Chung D, Slogoff M, Ehlers R, Hellmich M, Saito H, Uchida T, Evers B: Cyclooxygenase-2 gene disruption attenuates the severity of acute pancreatitis and pancreatitisassociated lung injury. Gastroenterology 2002; 123:1311-1322.

65 Bhatia M, Saluja AK, Hofbauer B, Frossard JL, Lee HS, Castagliuolo I, Wang CC, Gerard N, Pothoulakis C, Steer ML: Role of substance P and the neurokinin-1 receptor in acute pancreatitis and pancreatitis-associated lung injury. Proc Natl Acad Sci USA 1998;95:4760-4765.

66 Bhatia M, Slavin J, Cao Y, Basbaum AI, Neoptolemos JP: Preprotachykinin-A gene deletion protects mice against acute pancreatitis and associated lung injury. Am J Physiol 2003; 284:G830-G836.

67 Bhatia M, Saluja AK, Singh VP, Frossard JL, Lee HS, Bhagat L, Gerard C, Steer ML: Complement factor C5a exerts an anti-inflammatory effect in acute pancreatitis and associated lung injury. Am J Physiol 2001;280:G974-G978.

68 Demols A, Le Moine O, Desalle F, Quertinmont E, Van Laethem JL, Deviere J: $\mathrm{CD} 4^{+} \mathrm{T}$ cells play an important role in acute experimental pancreatitis in mice. Gastroenterology 2000; 118:582-590.

69 Mayer JM, Laine VJ, Kolodziej S, Nevalainen TJ, Beger HG: Acute pancreatitis in transgenic mice expressing human group IIA phospholipase $A_{2}$. Pancreas 2002;25:188-191.

70 Grippo PJ, Nowlin PS, Cassaday RD, Sandgren EP: Cell-specific transgene expression from a widely transcribed promoter using $\mathrm{Cre} /$ lox in mice. Genesis 2002;32:277-286.

71 Aguirre AJ, Bardeesy N, Sinha M, Lopez L, Tuveson DA, Horner J, Redston MS, DePinho RA: Activated K-ras and Ink4a/Arf deficiency cooperate to produce metastatic pancreatic ductal adenocarcinoma. Genes Dev 2003;17: 3112-3126. 